\title{
CXCL8, IL-1 $\beta$ and SCD200 are pro-inflammatory cytokines and their levels increase in the circulation of breast carcinoma patients
}

\author{
BETUL CELIK $^{1}$, ARZU DIDEM YALCIN ${ }^{2,3}$, GIZEM ESRA GENC ${ }^{4}$, \\ TANGUL BULUT $^{1}$, SIBEL KULOGLU GENC ${ }^{4}$ and SAADET GUMUSLU ${ }^{4}$
}

\begin{abstract}
Departments of ${ }^{1}$ Pathology and ${ }^{2}$ Department of Internal Medicine, Allergy and Clinical Immunology Unit, Antalya Training and Research Hospital, 07100 Antalya, Turkey; ${ }^{3}$ Genomics Research Center, Academia Sinica, Taipei 115, Taiwan, R.O.C.;

${ }^{4}$ Department of Medical Biochemistry, Faculty of Medicine, Akdeniz University, 07070 Antalya, Turkey
\end{abstract}

Received March 23, 2016; Accepted June 3, 2016

DOI: 10.3892/br.2016.709

\begin{abstract}
The influence of biomarkers on carcinogenesis has been investigated extensively. Whether they promote carcinogenesis or work against cancer development remains to be elucidated. To the best of our knowledge, the novel molecule cluster of differentiation 200 (CD200) has not been studied on human breast cancer subjects. The present study aimed to evaluate interleukin-1 $\beta$ (IL-1 $\beta$ ), C-X-C motif chemokine ligand 8 (CXCL8), cancer antigen 15.3 (CA 15.3) and the soluble CD200 (sCD200) levels in the serum samples of breast carcinoma patients in order to predict their role in breast carcinoma. The subjects included individuals with early and advanced stage breast cancers, as well as healthy controls. Commercially available ELISA kits were used to measure the serum concentrations of sCD200, IL-1 $\beta$, CXCL8, CA 15.3, C-reactive protein (CRP) and leukocyte count. A total of 130 subjects were recruited; 50 early stage cancer, 50 advanced stage and 30 control subjects. Serum sCD200, CXCL8, IL-1 $\beta$ and CRP levels were significantly higher in the early as well as the advanced stage breast cancer patients compared to the control group. The level of CA 15.3 was statistically different between early and advanced stage. There were significant positive correlations between IL-1 $\beta$ and CXCL8, and IL-1 $\beta$ and serum sCD200 levels in the control group. These correlations did not persist in the early or the advanced stage cancer groups except CRP and CA 15.3, but
\end{abstract}

Correspondence to: Dr Betul Celik, Department of Pathology, Antalya Training and Research Hospital, Varlik Mahallesi Kazim Karabekir Cad, 07100 Antalya, Turkey

E-mail: bet_celik@yahoo.com

Abbreviations: BMI, body mass index; CD200, cluster of differentiation 200; CRP, C-reactive protein; CXCL8, C-X-C motif chemokine ligand 8; DC, dendritic cell; IL, interleukin; NK, natural killer cell; sCD200, soluble CD200 antibody; TGF, transforming growth factor; TNF, tumor necrosis factor

Key words: CD200, IL-1 $\beta$, CXCL8, cancer, breast, obesity new correlations appeared between serum sCD200 level and leukocyte count for advanced stage breast cancer group. Multivariate regression correlation analysis revealed positive correlation between IL-1 $\beta$ and sCD200; and IL-1 $\beta$ and CXCL8. In conclusion, sCD200, CXCL8, CA 15.3 and IL-1 $\beta$ are proinflammatory molecules and their levels are influenced in breast cancer patients.

\section{Introduction}

Cancer cells transfected with $\mathrm{C}-\mathrm{X}-\mathrm{C}$ motif chemokine ligand 8 [CXCL8; also known as interleukin-8 (IL-8)] show increased cellular proliferation, cell migration and invasion based on functional assays (1). Previous studies have shown that CXCL8 and its receptors, CXCR1 and CXCR2, were significantly upregulated in colorectal cancers and acted as regulators of proliferation, angiogenesis and metastasis (2-4). Dimberg et al (5) reported that high plasma levels of CXCL8 tend to be correlated with distant metastasis, indicating an advanced disease stage. Thus far, the serum level of CXCL8 in patients with breast carcinoma has not been investigated extensively.

Certain cytokines lead to an influx of macrophages into adipose tissue $(6,7)$. These recruited macrophages in turn secrete cytokines, including ILs. IL-1 $\beta$ is a proinflammatory cytokine against infections; however, it also has a role in the pathogenesis of cancers $(8,9)$. Intratumoral levels of IL- $1 \beta$ are significantly higher in breast cancer compared to the normal adjacent breast tissue (10).

Soluble cluster of differentiation 200 (sCD200) is a cell surface membrane glycoprotein expressed on macrophages and reported to have a key role in the regulation of the immune system. sCD200 was shown to attenuate tumor necrosis factor- $\alpha$ (TNF- $\alpha)$ production in vivo and was associated with suppression of natural killer cells $(11,12)$. CD200 is considered to act through its receptor to inhibit inflammation. In carcinogenesis, the overall function of sCD200 is immune evasion of tumor cells (13). The role of CD200 in breast cancer progression and metastasis has been studied in animal breast carcinoma model, where CD200 overexpression resulted in increased lymph node metastasis (14). By contrast, CD200 expression by melanocytes resulted in decreased lung metastasis (15) and decreased metastatic growth of breast 
carcinoma cells (16). Thus far, sCD200 has not been studied on human breast carcinoma subjects.

The present study focused on IL-1 $\beta$, CXCL8, cancer antigen 15.3 (CA 15.3) and sCD200 in breast cancer patients. Leukocyte count and C-reactive protein (CRP) levels were assessed at the same time to allow correlation analysis of these well-known proinflammatory parameters with the novel molecules.

\section{Materials and methods}

Subjects. The subjects were all females with early and advanced stage (metastatic) breast cancers and healthy controls without any known malignancy. A total of 100 subjects (50 early and 50 advanced stage) and 30 controls were recruited at the Akdeniz University Hospital. The exclusion criteria included autoimmune and rheumatological diseases, hepatitis B, hepatitis $\mathrm{C}$ and human immunodeficiency virus positivity. The Institutional Review Board of Akdeniz University Faculty of Medicine approved this study, and all participants provided informed consent.

Weight and blood analysis. Weight (in kilograms) was measured in light clothing, without shoes, to the nearest $0.1 \mathrm{~kg}$. Subsequent to overnight fasting, blood samples were obtained from all subjects. The serum was separated by centrifugation of the blood samples at $1,500 \mathrm{x}$ for $10 \mathrm{~min}$ at $4^{\circ} \mathrm{C}$. The serum samples were stored at $-80^{\circ} \mathrm{C}$ until analytical measurements were performed.

Analysing serum levels. Commercially available ELISA kits were used to measure the serum concentrations of sCD200 (cat. no. SEK10886; SinoBiological, Inc., Beijing, China), IL-1 $\beta$ (cat. no. 851.610.005; Diaclone, Besançon, France), CXCL8 (cat. no. 555244; BD OptEIA kit, BD Biosciences, San Jose, CA, USA), CA 15.3 (Roche Diagnostics GmbH, Mannheim, Germany) leukocyte count (Siemens ADVIA 2120i; Siemens AG, Munich, Germany) and CRP (Roche Diagnostics, Indianapolis, IN, USA) according to the manufacturer's recommended protocols.

Statistical analysis. Results are presented as mean \pm standard error of the mean and median \pm standard deviation. Comparison of the parameters between two groups was performed using independent samples t-test. The association between the variables was determined using Pearson correlation analysis. $\mathrm{P}<0.05$ was considered to indicate a statistical significance difference. Statistical analyses were performed using SPSS 18.0 (IBM Corp., Armonk, NY, USA).

The data were evaluated using the StataMP software package, version 12.1 (StataCorp, College Station, TX, USA) on a Mac Pro $2 \times 2.93 \mathrm{GHz}, 2 * 6$ Core Intel Xeon system with 24 GB RAM using Mac OS X 10.7.4 (Apple, Cupertino, CA, USA). In general, a type I error level of $\mathrm{P}<0.05$ was used for the statistical analysis. The Wilcoxon matched pairs signed-rank test was used to assess the differences in the variables prior to and 3 months after the onset of treatment. Correlation tables were calculated for all the variables. Furthermore, a multivariate correlation/regression analysis was applied to the data, using the survival as the dependent variable.

\section{Results}

Subject characteristics. The subjects were individuals with early and advanced stage breast cancer and healthy controls. A total of 100 subjects (50 early and 50 advanced stage cancers) and 30 healthy control were recruited. Ages ranged from 36 to 55 years (mean, 41.09, 51.71 and 51.60 years for the control, early stage cancer and advanced stage cancer groups, respectively). The characteristics of the overall study population are listed in Table I. Although not intended, all the studied patients and control groups were overweight [body mass index (BMI) $\geq 25$ and $<30 \mathrm{~kg} / \mathrm{m}^{2} ; \mathrm{n}=130$ ). Table I shows the characteristics of the control group, and the early and advanced stage breast cancer subjects. All parameters studied were increased when compared to the control. Serum sCD200, CXCL8, IL-1 $\beta$ and CRP levels were all significantly higher in early and advanced stage breast cancer patients (Table I). The sCD200 level of the control group was $7.96 \pm 0.37 \mathrm{pg} / \mathrm{ml}$, while it was $10.90 \pm 0.46 \mathrm{pg} / \mathrm{ml}(\mathrm{p}=0.001)$ and $10.60 \pm 0.40 \mathrm{pg} / \mathrm{ml}(\mathrm{p}=0.001)$ in the early and advanced stage breast cancer groups, respectively (Table I). The CXCL8 level of the control group was $13.91 \pm 0.51 \mathrm{pg} / \mathrm{ml}$, and $16.49 \pm 0.50 \mathrm{pg} / \mathrm{ml}(\mathrm{p}=0.002)$ and $17.13 \pm 0.71 \mathrm{pg} / \mathrm{ml}(\mathrm{p}=0.001)$ in the early and advanced stage breast cancer groups, respectively. The IL-1 $\beta$ level in the control group was $20.36 \pm 1.36 \mathrm{pg} / \mathrm{ml}$, and it was $32.26 \pm 1.37 \mathrm{pg} / \mathrm{ml}(\mathrm{p}=0.001)$ and $34.58 \pm 1.75 \mathrm{pg} / \mathrm{ml}(\mathrm{p}=0.001)$ in the early and advanced stage breast cancer groups respectively. The CA 15.3 level of the control group was zero, while it was $21.00 \pm 1.77$ and $28.10 \pm 2.86 \mathrm{IU} / \mathrm{ml}$ in the early and advanced stage breast cancer groups, respectively. For the CRP level, the control group had a lower level of $29.57 \pm 0.67 \mathrm{IU} / 1$, while it was $41.31 \pm 0.51 \mathrm{IU} / 1(\mathrm{p}=0.001)$ and $39.17 \pm 0.66 \mathrm{IU} / 1(\mathrm{p}=0.001)$ in the early and advanced stage breast cancer groups, respectively. The differences in CRP between the early and advanced stage breast cancer groups were statistically significant $(\mathrm{p}=0.024)$.

Correlation analysis. A correlation analysis was performed to investigate whether circulating sCD200, CXCL8, CA15.3 and IL-1 $\beta$ levels were associated with age, BMI, CRP and leukocyte count. The level of CA 15.3 was statistically significant between the early and advanced stage cancer group $(\mathrm{p}=0.040)$ There were significant positive correlations between the serum IL-1 $\beta$ and serum sCD200 level $(r=0.570$, $\mathrm{p}=0.011$ ); and IL-1 $\beta$ and CXCL8 ( $\mathrm{r}=0.779, \mathrm{p}=0.001)$ within the control group. These correlations did not persist within the early or advanced stage cancer groups; however, new correlations appeared between the serum sCD200 level and leukocyte count $(\mathrm{r}=0.546, \mathrm{p}=0.009)$ for the advanced stage breast cancer group. The advanced breast cancer group also revealed a positive correlation between CRP and CA 15.3 $(\mathrm{r}=0.410, \mathrm{p}=0.013)$.

Subsequent to adjusting for the early and advanced stage breast cancer groups, the correlation between SCD200 and leukocyte count $(\mathrm{r}=0.359, \mathrm{p}=0.021)$ and $\mathrm{CRP}$ and CA15.3 $(\mathrm{r}=0.264, \mathrm{p}=0.032)$ remained significant. Multivariate regression correlation analysis revealed a positive correlation between IL-1 $\beta$ and CD200 $(r=0.570, p=0.011)$; and IL-1 $\beta$ and CXCL8 $(\mathrm{r}=0.810, \mathrm{p}=0.001)$, which were observed in the univariate analysis for control group. 
Table I. Patient characteristics and biomarkers levels in the control, early stage and late stage breast cancer subjects.

\begin{tabular}{|c|c|c|c|c|c|c|}
\hline Parameter & Control $(n=30)$ & Early stage $(\mathrm{n}=50)$ & P-value ${ }^{a}$ & Late stage $(n=50)$ & P-value ${ }^{b}$ & P-value ${ }^{c}$ \\
\hline Age, years & $41.09 \pm 1.97$ & $51.71 \pm 1.48$ & NA & $51.60 \pm 1.57$ & NA & NA \\
\hline $\mathrm{BMI}, \mathrm{kg} / \mathrm{m}^{2}$ & $26.07 \pm 1.12$ & $29.47 \pm 0.73$ & NA & $28.96 \pm 0.72$ & NA & NA \\
\hline $\mathrm{sCD} 200, \mathrm{pg} / \mathrm{ml}$ & $7.96 \pm 0.37$ & $10.90 \pm 0.46$ & 0.001 & $10.60 \pm 0.40$ & 0.001 & NA \\
\hline IL-1 $\beta, \mathrm{pg} / \mathrm{ml}$ & $20.36 \pm 1.36$ & $32.26 \pm 1.37$ & 0.001 & $34.58 \pm 1.75$ & 0.001 & NA \\
\hline CXCL8, pg/ml & $13.91 \pm 0.51$ & $16.49 \pm 0.50$ & 0.002 & $17.13 \pm 0.71$ & 0.001 & NA \\
\hline CRP, IU/1 & $29.57 \pm 0.67$ & $41.31 \pm 0.51$ & 0.001 & $39.17 \pm 0.66$ & 0.001 & 0.024 \\
\hline CA $15.3, \mathrm{IU} / \mathrm{ml}$ & 0.00 & $21.00 \pm 1.77$ & NA & $28.10 \pm 2.86$ & NA & 0.040 \\
\hline Leukocytes, $1,000 / \mathrm{mm}^{3}$ & $8.48 \pm 0.41$ & $7.67 \pm 0.30$ & NA & $7.25 \pm 0.37$ & NA & Naat clean \\
\hline
\end{tabular}

BMI, body mass index; sCD200, soluble cluster of differentiation 200; IL, interleukin; CXCL8, C-X-C motif chemokine ligand 8; CRP, C-reactive protein; CA 15.5, cancer antigen 15.3; NA, not available; ${ }^{\mathrm{a}}$ control vs. early stage cancer; ${ }^{\mathrm{b}}$ control vs. late stage cancer; ${ }^{\mathrm{c}}$ early vs. late stage cancer.

\section{Discussion}

An association between the development of cancer and inflammation has repeatedly been reported (17-19). Overexpression of CXCL8, an angiogenic factor, by tumor cells is well known (20) and its level was correlated with breast and colon cancer progression (21-24). IL-1 $\beta$ is another proinflammatory molecule. It is present in the extracellular space and its level is undetectable when there is no inflammation. IL-1 $\beta$-deficient mice experienced slow tumor progression $(25,26)$. It appears that inflammation provides an environment for tumor cells. Its presence in breast cancer was correlated with aggressiveness of the tumor $(27,28)$. These studies were conducted on breast cancer tissues in vitro and the involvement of the circulatory system has not been investigated previously. The present results represented the circulating level of these cytokines and higher levels of CXCL8 and IL-1 $\beta$ were identified in the serum of breast cancer patients compared to the control group. The study also showed that there was an increased level of CRP in the serum of breast cancer patients when compared to the control group, which indicates a proinflammatory state among breast cancer patients.

The importance of the inflammatory responses in determining disease progression in patients with cancer is recognized. In particular, white cell counts (neutrophil), platelet counts and acute-phase proteins have been reported to have a prognostic value. CRP is a classical acute-phase reactant protein from the pentraxin family. CRP is increased in the circulation in response to acute inflammation, infection and tissue damage. Studies reporting a higher level of CRP in breast carcinoma cells claimed that elevated CRP levels were associated with an increased risk of breast cancer (29) or had a prognostic value in patients with breast cancer (30). By contrast, the present study indicates that the cancer state in the body increases CRP levels to fight against tumor cells. CXCL8 and IL-1 $\beta$ are there as part of an inflammatory response that is fighting against tumor.

One aspect of the present study was that there was a positive correlation between IL-1 $\beta$ and CD200, and IL-1 $\beta$ and CXCL8 in the overweight control group. There is a low-grade chronic inflammation state in obese people and serum CRP and CXCL8 levels are increased $(31,32)$. However, the groups in the present study consisted of overweight subjects, not obese. Adipose tissue functions as an endocrine organ and secretes bioactive molecules $(33,34)$, and several epidemiological studies have established a consistent association between obesity and cancer (31). One study found a positive association between CRP levels and postmenopausal breast cancer risk, which was restricted to women with excess adiposity (35). Considering the association of CXCL8 with obesity (36), adipose tissue in the breast parenchyma may affect cytokine levels.

Studies have reported that the CD200/CD200-receptor interaction has an anti-inflammatory effect $(37,38)$. It increases the anti-inflammatory cytokines IL-10, IL-4, IL-5, TGF- $\beta$ and regulatory $\mathrm{T}$ cells, decreases IL-1, IL-2, IL-6, IL-12, CTL, TNF- $\alpha$ and leukocytes, and increases tumor progression (39-41). Genetically engineered mice that overexpressed CD200 showed that the metastatic growth of breast tumor cells increased (14). By contrast, highly aggressive, but similar, breast carcinoma cells had decreased metastatic growth in a CD200-overexpressed host (16). These two opposing effects may be explained by the bidirectional characteristic of CD200. However, the present study observed higher sCD200 level in breast carcinoma patients compared to the control group. Its level was positively correlated with proinflammatory cytokine IL-1 $\beta$ in the control group and the leukocyte count in the advanced stage breast carcinoma group. These results indicate the proinflammatory effects of this cytokine. Its proinflammatory effect has been detected in our previous studies conducted on allergic patients $(42,43)$. We hypothesize that a decreased metastatic growth in a CD200-overexpressed host (16) reflects its proinflammatory property and a higher sCD200 level observed in the cancer group is the indication of the host reaction against cancer development in the present study. A higher level observed in the tumor does not reflect its anti-inflammatory or tumorigenic property, but the inflammatory reaction of the host against tumor development. In a previous study (15), the activation of the CD200 receptor, which is expressed mostly by myeloid cells (44), may have resulted in less CD200-negative melanoma cells due to the antigen masking effort of the tumors to escape immune surveillance. 
The correlation that was apparent between CRP and CA 15.3 in the present study is important. Previously, a significant decrease in CA 15.3 was observed following immunotherapy for breast cancer (45). Furthermore, the correlation between CA 15.3 and CRP has been documented in different types of cancer patients after the inhibition of pro-inflammatory pathways by vitamin C (46). To the best of our knowledge, this is the first study demonstrating such a correlation in breast cancer.

In conclusion, $\mathrm{sCD} 200, \mathrm{CXCL} 8, \mathrm{IL}-1 \beta$ and CRP are proinflammatory molecules and their levels are influenced in breast cancer. Further studies comparing obese $\left(\mathrm{BMI} \geq 30 \mathrm{~kg} / \mathrm{m}^{2}\right)$ and non-obese breast carcinoma subjects may allow novel insight regarding obesity, cancer and inflammatory markers.

\section{Acknowledgements}

The authors would like to thank Mr. David M. Silverman for his editing.

\section{References}

1. Ning Y, Manegold PC, Hong YK, Zhang W, Pohl A, Lurje G, Winder T, Yang D, LaBonte MJ, Wilson PM, et al: Interleukin-8 is associated with proliferation, migration, angiogenesis and chemosensitivity in vitro and in vivo in colon cancer cell line models. Int J Cancer 128: 2038-2049, 2011.

2. Varney ML, Singh S, Li A, Mayer-Ezell R, Bond R and Singh RK: Small molecule antagonists for CXCR2 and CXCR1 inhibit human colon cancer liver metastases. Cancer Lett 300: 180-188, 2011.

3. Oladipo O, Conlon S, O'Grady A,PurcellC,Wilson C,Maxwell PJ, Johnston PG, Stevenson M, Kay EW, Wilson RH, et al: The expression and prognostic impact of CXC-chemokines in stage II and III colorectal cancer epithelial and stromal tissue. Br J Cancer 104: 480-487, 2011.

4. Chen Y, Shi M, Yu GZ, Qin XR, Jin G, Chen P and Zhu MH: Interleukin-8, a promising predictor for prognosis of pancreatic cancer. World J Gastroenterol 18: 1123-1129, 2012.

5. Dimberg J, Ström K, Löfgren S, Zar N, Lindh M and Matussek A: DNA promoter methylation status and protein expression of interleukin-8 in human colorectal adenocarcinomas. Int J Colorectal Dis 27: 709-714, 2012

6. Chen A, Mumick S, Zhang C, Lamb J, Dai H, Weingarth D, Mudgett J, Chen H, MacNeil DJ, Reitman ML, et al: Diet induction of monocyte chemoattractant protein-1 and its impact on obesity. Obes Res 13: 1311-1320, 2005.

7. Sartipy P and Loskutoff DJ: Monocyte chemoattractant protein 1 in obesity and insulin resistance. Proc Natl Acad Sci USA 100: 7265-7270, 2003.

8. Maker AV, Katabi N, Qin LX, Klimstra DS, Schattner M, Brennan MF, Jarnagin WR and Allen PJ: Cyst fluid interleukin-1beta (IL1beta) levels predict the risk of carcinoma in intraductal papillary mucinous neoplasms of the pancreas. Clin Cancer Res 17: 1502-1508, 2011.

9. Bhat IA, Naykoo NA, Qasim I, Ganie FA, Yousuf Q, Bhat BA, Rasool R, Aziz SA and Shah ZA: Association of interleukin 1 beta (IL-1 $\beta$ ) polymorphism with mRNA expression and risk of non small cell lung cancer. Meta Gene 2: 123-133, 2014.

10. Abrahamsson A, Morad V, Saarinen NM and Dabrosin C: Estradiol, tamoxifen, and flaxseed alter IL-1 $\beta$ and IL-1Ra levels in normal human breast tissue in vivo. J Clin Endocrinol Metab 97: E2044-E2054, 2012.

11. Gorczynski R, Boudakov I and Khatri I: Peptides of CD200 modulate LPS-induced TNF- $\alpha$ induction and mortality in vivo. J Surg Res 145: 87-96, 2008.

12. Coles SJ, Wang EC, Man S, Hills RK, Burnett AK, Tonks A and Darley RL: CD200 expression suppresses natural killer cell function and directly inhibits patient anti-tumor response in acute myeloid leukemia. Leukemia 25: 792-799, 2011.

13. Celik B, Didem Yalcin A, Esra Genc G and Gumuslu S: Proteomics pattern of peritoneal sApo-2L but not CD200 (OX-2) as a possible screening biomarker for metastatic ovarian, endometrial and breast carcinoma. J BUON 20: 280-286, 2015.
14. Gorczynski RM, Clark DA, Erin N and Khatri I: Role of CD200 expression in regulation of metastasis of EMT6 tumor cells in mice. Breast Cancer Res Treat 130: 49-60, 2011.

15. Talebian F, Liu JQ, Liu Z, Khattabi M, He Y, Ganju R and Bai XF: Melanoma cell expression of CD200 inhibits tumor formation and lung metastasis via inhibition of myeloid cell functions. PLoS One 7: e31442, 2012.

16. Erin N, Podnos A, Tanriover G, Duymus Ö, Cote E, Khatri I and Gorczynski RM: Bidirectional effect of CD200 on breast cancer development and metastasis, with ultimate outcome determined by tumor aggressiveness and a cancer-induced inflammatory response. Oncogene 34: 3860-3870, 2015.

17. Grivennikov SI, Greten FR and Karin M: Immunity, inflammation, and cancer. Cell 140: 883-899, 2010.

18. García-Rodríguez LA and Huerta-Alvarez C: Reduced risk of colorectal cancer among long-term users of aspirin and nonaspirin nonsteroidal antiinflammatory drugs. Epidemiology 12: 88-93, 2001.

19. Condeelis J and Pollard JW: Macrophages: Obligate partners for tumor cell migration, invasion, and metastasis. Cell 124: 263-266, 2006.

20. Waugh DJ and Wilson C: The interleukin-8 pathway in cancer. Clin Cancer Res 14: 6735-6741, 2008.

21. Wang J, He Q, Shao YG and Ji M: Chemokines fluctuate in the progression of primary breast cancer. Eur Rev Med Pharmacol Sci 17: 596-608, 2013.

22. Doll D, Keller L, Maak M, Boulesteix AL, Siewert JR, Holzmann B and Janssen KP: Differential expression of the chemokines GRO-2, GRO-3, and interleukin-8 in colon cancer and their impact on metastatic disease and survival. Int $\mathbf{J}$ Colorectal Dis 25: 573-581, 2010.

23. Celik B, Yalcin AD, Bisgin A, Dimitrakopoulou-Strauss A, Kargi A and Strauss LG: Level of TNF-related apoptosis-inducing-ligand and CXCL8 correlated with 2-[18F] Fluoro-2-deoxy-D-glucose uptake in anti-VEGF treated colon cancers. Med Sci Monit 19: 875-882, 2013.

24. Narita D, Seclaman E, Anghel A, Ilina R, Cireap N, Negru S, Sirbu IO, Ursoniu S and Marian C: Altered levels of plasma chemokines in breast cancer and their association with clinical and pathological characteristics. Neoplasma 63: 141-149, 2016.

25. Shirakawa F, Saito K, Bonagura CA, Galson DL, Fenton MJ, Webb AC and Auron PE: The human prointerleukin $1 \beta$ gene requires DNA sequences both proximal and distal to the transcription start site for tissue-specific induction. Mol Cell Biol 13: 1332-1344, 1993.

26. Apte RN, Krelin Y, Song X, Dotan S, Recih E, Elkabets M, Carmi Y, Dvorkin T, White RM, Gayvoronsky L, et al: Effects of micro-environment- and malignant cell-derived interleukin-1 in carcinogenesis, tumour invasiveness and tumour-host interactions. Eur J Cancer 42: 751-759, 2006.

27. Jin L, Yuan RQ, Fuchs A, Yao Y, Joseph A, Schwall R, Schnitt SJ, Guida A, Hastings HM, Andres J, et al: Expression of interleukin-1 $\beta$ in human breast carcinoma. Cancer 80: 421-434, 1997.

28. Miller LJ, Kurtzman SH, Anderson K, Wang Y, Stankus M, Renna M, Lindquist R, Barrows G and Kreutzer DL: Interleukin-1 family expression in human breast cancer: Interleukin-1 receptor antagonist. Cancer Invest 18: 293-302, 2000.

29. Guo L, Liu S, Zhang S, Chen Q, Zhang M, Quan P, Lu J and Sun X: C-reactive protein and risk of breast cancer: A systematic review and meta-analysis. Sci Rep 5: 10508, 2015.

30. Han Y, Mao F, Wu Y, Fu X, Zhu X, Zhou S, Zhang W, Sun Q and Zhao Y: Prognostic role of C-reactive protein in breast cancer: A systematic review and meta-analysis. Int J Biol Markers 26: 209-215, 2011.

31. Ramos-Nino ME: The role of chronic inflammation in obesity-associated cancers. ISRN Oncol 2013: 697521, 2013.

32. Scotece M, Conde J, Gómez R, López V, Lago F, Gómez-Reino JJ and Gualillo O: Beyond fat mass: Exploring the role of adipokines in rheumatic diseases. ScientificWorldJournal 11: 1932-1947, 2011.

33. Fietta P and Delsante G: Focus on adipokines. Theor Biol Forum 106: 103-129, 2013.

34. Alfadda AA: Circulating adipokines in healthy versus unhealthy overweight and obese subjects. Int J Endocrinol 2014: 170434, 2014.

35. Dossus L, Jimenez-Corona A, Romieu I, Boutron-Ruault MC, Boutten A, Dupré T, Fagherazzi G, Clavel-Chapelon F and Mesrine S: C-reactive protein and postmenopausal breast cancer risk: Results from the E3N cohort study. Cancer Causes Control 25: 533-539, 2014. 
36. Nehete P, Magden ER, Nehete B, Hanley PW, Abee CR: Obesity related alterations in plasma cytokines and metabolic hormones in chimpanzees. Int J Inflam 2014: 856749, 2014.

37. Gorczynski RM: CD200:CD200R-mediated regulation of immunity. ISRN Immunology 2012: 682168, 2012.

38. Rijkers ES, de Ruiter T, Baridi A, Veninga H, Hoek RM and Meyaard L: The inhibitory CD200R is differentially expressed on human and mouse T and B lymphocytes. Mol Immunol 45: 1126-1135, 2008.

39. Holmannová D, Kolácková M, Kondélková K, Kunes P, Krejsek J and Andrýs C: CD200/CD200R paired potent inhibitory molecules regulating immune and inflammatory responses; Part I: CD200/CD200R structure, activation, and function. Acta Med (Hradec Kralove) 55: 12-17, 2012.

40. Fallarino F, Asselin-Paturel C, Vacca C, Bianchi R, Gizzi S, Fioretti MC, Trinchieri G, Grohmann U and Puccetti P: Murine plasmacytoid dendritic cells initiate the immunosuppressive pathway of tryptophan catabolism in response to CD200 receptor engagement. J Immunol 173: 3748-3754, 2004.

41. Jenmalm MC, Cherwinski H, Bowman EP, Phillips JH and Sedgwick JD: Regulation of myeloid cell function through the CD200 receptor. J Immunol 176: 191-199, 2006.
42. Yalcin AD, Cilli A, Bisgin A, Strauss LG and Herth F: Omalizumab is effective in treating severe asthma in patients with severe cardiovascular complications and its effects on sCD200, d-dimer, CXCL8, 25-hydroxyvitamin D and IL-1 $\beta$ levels. Expert Opin Biol Ther 13: 1335-1341, 2013.

43. Tural Onur S, Yalcin AD, Celik B and Gumuslu S: Evaluation of d-dimer, CXCL8, homocysteine, eosinophil cationic peptide, 25(OH)-vitamin D and immunomodulatory OX-2 levels in allergic patients. J Asthma 52: 123-127, 2015.

44. Wright GJ, Cherwinski H, Foster-Cuevas M, Brooke G, Puklavec MJ, Bigler M, Song Y, Jenmalm M, Gorman D, McClanahan T, et al: Characterization of the CD200 receptor family in mice and humans and their interactions with CD200. J Immunol 171: 3034-3046, 2003.

45. Nicolini A, Rossi G, Ferrari P and Carpi A: Clinical and laboratory patterns during immune stimulation in hormone responsive metastatic breast cancer. Biomed Pharmacother 68: 171-178, 2014.

46. Mikirova N, Casciari J, Rogers A and Taylor P: Effect of high-dose intravenous vitamin $\mathrm{C}$ on inflammation in cancer patients. J Transl Med 10: 189, 2012. 